BOURGUIGNON, Ana Maria; GRISOTTI, Marcia. A humanização do parto e nascimento no Brasil nas trajetórias de suas pesquisadoras. História, Ciências, Saúde - Manguinhos, Rio de Janeiro, v.27, n.2, abr.-jun. 2020, p.485-502.

\title{
A humanização do parto e nascimento no Brasil nas trajetórias de suas pesquisadoras
}

\author{
The humanization of \\ childbirth in Brazil as seen \\ in the trajectories of its \\ researchers
}

Ana Maria Bourguignon ${ }^{i}$

' Doutoranda, Programa de Pós-graduação em Ciências Sociais Aplicadas/ Universidade Estadual de Ponta Grossa e Instituto de Higiene e Medicina Tropical/Universidade Nova de Lisboa.

Ponta Grossa - PR - Brasil

anamariabourg@gmail.com

orcid.org/0000-0001-9293-6719

\section{Marcia Grisottii}

ii Professora, coordenadora do Núcleo de Ecologia Humana e Sociologia da Saúde/Universidade Federal de Santa Catarina. Florianópolis - SC - Brasil

orcid.org/0000-0003-0389-7100

grisotti@fastlane.com.br

Recebido em 10 maio 2018.

Aprovado em 4 fev. 2019.

http://dx.doi.org/10.1590/S0104-59702020000200010

Resumo

Trata-se de pesquisa qualitativa que analisou as trajetórias de pesquisadoras que produziram teses e/ou dissertações sobre humanização do parto e nascimento em programas de pósgraduação brasileiros. As questões que nortearam a investigação foram: como as pesquisadoras detectam a emersão da concepção de humanização para o parto e nascimento em suas trajetórias profissionais? Como essas trajetórias se relacionam com a história do movimento de humanização do parto e nascimento no Brasil? O referencial teórico foucaultiano contribuiu para identificar as posições ocupadas pelas pesquisadoras no discurso em prol da humanização, seus lugares de enunciação, bem como relações de saber e poder que permeiam a construção do movimento pela humanização do parto e nascimento no Brasil.

Palavras-chave: humanização do parto e nascimento; teses e dissertações; ordem do discurso.

Abstract

This qualitative research analyzes the trajectories of researchers who have produced master's and doctoral dissertations and theses on the humanization of childbirth in Brazil. The questions guiding the investigation are: How did the researchers detect the emergence of the conception of humanization of childbirth in their professional trajectories? How do these trajectories interrelate with the movement for the humanization of childbirth in Brazil? The Foucauldian theoretical framework adopted helps identify the positions occupied by the researchers in the discourse in favor of humanization, their places of utterance, and relations of knowledge and power that permeated the construction of the movement for the humanization of childbirth in Brazil.

Keywords: humanization of childbirth; theses and dissertations; order of discourse. 
$\mathrm{E}$ ste artigo analisa as trajetórias de pesquisadoras que escreveram tese e/ou dissertação sobre humanização do parto e nascimento no Brasil, tendo como base as justificativas para escolha do objeto apresentada pelas próprias doutorandas e mestrandas em seus trabalhos, bem como entrevistas de apoio realizadas com cinco sujeitos. O objetivo é mostrar como as trajetórias dessas pesquisadoras estão articuladas com a história do movimento pela humanização do parto e nascimento no Brasil e, a partir disso, identificar a posição ocupada por esses sujeitos no discurso em defesa da humanização.

As mudanças de sentido, as reconfigurações de trajetórias são estruturadas e se estruturam nas malhas do discurso. O agir, o falar, o modo de ver o mundo se alteram nessas posições ocupadas pelos sujeitos. Posições que, ao mesmo tempo, se reforçam e demonstram sua existência por meio dos sujeitos, atravessando-os, existindo antes deles e para além deles em uma ordem de discurso (Foucault, 2011). Estar em um lugar não é somente uma vontade, é também uma obediência, é se adequar ao estabelecido, socializar-se. Nesse sentido, a educação para a profissão e o exercício profissional são espaços de socialização, de posições, hierarquias, valores que estão pressupostos nos enunciados emitidos e internalizados pelos indivíduos. Assim acontece nos discursos presentes na academia e no espaço profissional. $\mathrm{E}$ os momentos de mudança, de reposicionamento dos enunciados, são considerados rupturas para as trajetórias individuais, ainda que o discurso permaneça se alimentando desses diferentes significados para se reforçar e se opor a outros enunciados e a outros discursos.

O discurso de humanização do parto e nascimento por meio das modalidades enunciativas consubstancia-se na materialidade que confere ao discurso um lugar específico no tempo e no espaço, autorizando determinado sujeito e não outro a falar. Ao descrever as modalidades enunciativas do discurso, pretendemos especificar o lugar institucional de onde fala o sujeito (autora/autor de uma tese ou dissertação), que características são socialmente atribuídas a esse sujeito para poder dizer o que diz e para sua fala ser levada em consideração. Ainda, quais são as atribuições que os próprios sujeitos dão a si, estabelecendo a reflexibilidade que conecta sujeitos e instituições nas tramas do discurso. Ou seja, quem fala? Qual o status do indivíduo que fala? Que posição o sujeito que fala ocupa no discurso de humanização do parto e nascimento? Qual ou quais os lugares institucionais de onde o sujeito é autorizado a enunciar seu discurso? Em que corpo disciplinar e profissional saber e poder relacionam-se nas manifestações das autoras das teses e dissertações? (Foucault, 2005, p.56). Tendo como horizonte essa problemática, o presente artigo procura responder: como as pesquisadoras detectam a emersão da concepção de humanização para o parto e nascimento em suas trajetórias profissionais? Como essas trajetórias se relacionam com a história do movimento de humanização do parto e nascimento no Brasil?

Este texto está dividido em três partes. A primeira expõe os aspectos metodológicos para definição das teses e dissertações selecionadas para análise qualitativa. Na sequência, descreve as características da definição da humanização como modelo de atenção ao parto e nascimento com base nos trabalhos estudados. E, em seguida, apresenta as histórias e trajetórias do movimento de humanização do parto e nascimento no Brasil sob a perspectiva das pesquisadoras que produziram dissertação e ou tese sobre o tema em programas de pós-graduação brasileiros. 


\section{Corpus de pesquisa}

Foram selecionados 11 trabalhos a partir de uma pesquisa mais ampla que objetivou inventariar as teses e dissertações produzidas no Brasil de 1987 a 2012 com o tema humanização da assistência obstétrica e neonatal (Bourguignon, 2014). Do total de 379 trabalhos levantados em busca realizada no Banco de Teses da Capes, de março de 2012 a julho de 2013, realizou-se uma seleção por meio de métodos qualitativos e quantitativos. Primeiramente, foi feita uma análise quantitativa dos trabalhos para identificar os centros de pesquisa e pesquisadoras que realizaram tese e ou dissertação sobre a humanização do parto e nascimento.

A leitura sistemática de todos os resumos levou à pré-seleção de sessenta trabalhos que conceituavam, problematizavam ou historicizavam a humanização do parto e nascimento. Nesses foram aplicados nove critérios elaborados para escolha dos trabalhos, atribuindo-se um ponto para cada critério (Bourguignon, Grisotti, 2016):

(a) a universidade de origem estar entre aquelas com 25 ou mais teses e dissertações sobre o tema - Universidade Federal do Rio de Janeiro (UFRJ), Universidade Federal de Santa Catarina (UFSC), Fundação Oswaldo Cruz (Fiocruz), Universidade do Estado do Rio de Janeiro (Uerj) e Universidade de São Paulo (USP) contribuíram juntas com 36\% do total dos trabalhos;

(b) o programa de pós-graduação onde foi desenvolvido o trabalho figurar entre os cinco com maior produção sobre a temática - Enfermagem da UFSC, da UFRJ, da Uerj e da USP e Saúde da Mulher e da Criança da Fiocruz, os quais, somados, representaram 24\% do universo de teses e dissertações;

(c) a área de conhecimento do programa ${ }^{1}$ em que foi desenvolvida a tese ou dissertação corresponder àquelas com maior volume de trabalhos sobre o assunto - enfermagem $(48,8 \%)$, saúde coletiva (18,5\%), interdisciplinar (6,9\%), psicologia $(6,6 \%)$ e medicina II $(5,8 \%)$;

(d) tese de doutorado, por se tratar de uma modalidade de pesquisa que exige originalidade e contribuição significativa para o desenvolvimento do conhecimento científico;

(e) orientadora/orientador apresentar quatro ou mais orientações de dissertações e/ou teses sobre humanização do parto e nascimento;

(f) autora/autor ter realizado dissertação e tese sobre humanização do parto e nascimento, o que caracteriza trajetória de vinculação acadêmica com o tema;

(g) autora ou autor ter sido identificada(o) entre aqueles com cinco ou mais participações em bancas de defesa de dissertações e teses sobre humanização do parto e nascimento;

(h) ano de defesa anterior a 2000, para valorizar os primeiros registros, tendo em vista o interesse em compreender quando e como ocorre a emergência da produção científica no Brasil sobre humanização do parto e nascimento; ${ }^{2}$

(i) trajetória pública relacionada à humanização do parto e nascimento no Brasil; para isso, foi realizado um levantamento sobre a atuação profissional e vinculação das autoras e dos autores com movimentos sociais dedicados ao tema.

Uma limitação dos critérios expostos é serem os trabalhos selecionados oriundos de instituições de pós-graduação do eixo Sudeste-Sul, haja vista a intenção de analisar trabalhos representativos dos centros de pesquisa com maior volume de dissertações e teses sobre o 
tema. Pondera-se, por outro lado, que a concentração em estados dos eixos Sudeste-Sul é, em grande medida, um espelho da distribuição de programas de pós-graduação no país, conforme dados do Geocapes (Brasil, 2012). A análise da distribuição das teses e dissertações sobre humanização do parto e nascimento por região do país aponta que o Sudeste concentra mais de 53\% da produção, tendo Rio de Janeiro e São Paulo 47,7\% dos trabalhos no país; a região Nordeste aparece em segundo lugar com 20,6\%, seguida das regiões Sul (17,9\%), Centro-Oeste $(7,1 \%)$ e Norte $(1,1 \%)$.

Após a aplicação dos critérios, restaram 11 trabalhos que atingiram cinco ou mais pontos. A escolha das 11 teses e dissertações enfatizou a realidade de três centros de pesquisa sobre humanização, localizados no Rio de Janeiro, em São Paulo e Florianópolis, totalizando dez pesquisadores. São seis pesquisadores do Rio de Janeiro (Adriana Lenho de Figueiredo Pereira, Heloísa Lessa, Katia Ratto de Lima, Leila Gomes Ferreira de Azevedo, Marcos Augusto Bastos Dias, Maysa Luduvice Gomes), duas pesquisadoras de São Paulo (Carmem Simone Grilo Diniz e Ruth Hitomi Osava) e duas de Florianópolis (Odaléa Maria Brüggemann e Maria de Fátima Motta Zampieri). São três médicos (Katia Ratto é pediatra, Marcos Dias é obstetra e Carmen Simone Grilo Diniz é especialista em saúde pública) e sete enfermeiras com formação em obstetrícia. Além das teses e dissertações, realizamos como apoio quatro entrevistas: com Marcos Augusto Bastos Dias, Carmen Simone Grilo Diniz, Ruth Hitomi Osava, e com a professora da Faculdade de Enfermagem da Uerj Jane Márcia Progianti, os quais concordaram em participar da pesquisa e expor a transcrição de suas entrevistas, por meio de Termo de Consentimento Livre e Esclarecido.

Tendo como referente teórico-metodológico a análise arqueológica dos discursos de Foucault (2005), compreende-se que as teses e dissertações são produtos de enunciação do discurso de humanização do parto e nascimento e dispositivos de análise, pois permitem investigar como esse discurso delimita seu domínio; entende o parto e o nascimento como objetos; organiza, classifica, redefine, opõe conceitos e práticas da obstetrícia; reposiciona os sujeitos na assistência (mulheres, famílias, profissionais de saúde); estabelece estratégias, constrói uma narrativa histórica.

\section{A humanização como modelo de atenção ao parto e nascimento}

No Brasil, a humanização é uma expressão utilizada para qualificar demandas de movimentos sociais relacionadas aos cuidados prestados às mulheres durante a gestação, o parto e o puerpério. Conforme Diniz (2005), o termo passa a ser utilizado no país na década de 1990 para designar um novo modelo de atenção ao parto e nascimento que tem por fundamento as evidências científicas e os direitos humanos das usuárias dos serviços de saúde. É nesse sentido que, a partir de 2000, a humanização passa a designar os programas na área de saúde materna do governo federal. ${ }^{3}$ Como um novo modelo, a humanização é descrita nas teses e dissertações estudadas mediante o posicionamento crítico das autoras ao modelo de obstetrícia preponderante nos serviços de saúde brasileiros.

Para Ayres (2009, p.12), "entende-se por modelo de atenção à saúde a convergência de horizontes entre os diversos discursos acerca de modos de operar e gerir as tecnologias de atenção à saúde de indivíduos e populações". Paim (2001, p.7-8) define que um modelo de 
atenção à saúde consubstancia uma concepção sobre o uso de tecnologia para intervir em problemas e necessidades sociais da saúde.

Modelo não é padrão, não é exemplo, não é burocracia. Modelo é uma 'razão de ser' uma racionalidade. É uma espécie de 'lógica' que orienta a ação. 'Modelo de atenção à saúde' ou modelo assistencial não é uma forma de organizar serviços de saúde. Também não é um modo de administrar (gestão ou gerenciamento) o sistema e os serviços de saúde. Modelo de atenção é uma dada forma de combinar 'técnicas e tecnologias' para resolver problemas de saúde e atender necessidades de saúde individuais e coletivas. É uma maneira de organizar os 'meios de trabalho' (saberes e instrumentos) utilizados nas práticas ou processos de trabalho em saúde. Aponta como melhor combinar os 'meios técnico-científicos existentes para resolver problemas de saúde' individuais e/ ou coletivo. Corresponde à 'dimensão técnica' das práticas de saúde. Incorpora uma 'lógica' que orienta as intervenções técnicas sobre os problemas e necessidades de saúde (modelos de intervenção em saúde) (destaques no original).

Ao denominar um conjunto de práticas sob a alcunha da humanização como um "novo modelo", está se realizando um duplo movimento: (a) de que um conjunto de concepções e práticas em torno dos cuidados obstétricos pode ser tomado como um modelo, uma ideia que caracteriza sinteticamente procedimentos, conceitos e atribuições profissionais, em uma espécie de imagem do que deve ser o parto e o nascimento. Esse modelo não é somente da ordem do científico-biológico, mas também do antropológico. Há um conceito de "mulher", de "humano" envolvido nesse modelo; (b) de que um conjunto restrito de profissionais, mulheres e pesquisadores estão propondo uma nova concepção de cuidados no parto e nascimento que devem orientar práticas e rotinas nos serviços de saúde, o que caracteriza esse movimento acadêmico como uma estratégia de resistência ao modelo dominante de atenção ao parto e nascimento.

O sujeito humano, segundo Foucault (1995, p.233-235), ao se colocar "em relações de produção e de significação, é colocado em relações de poder muito complexas". Para compreender como essas relações de poder operam, Foucault propõe analisá-las por meio do que chama de "antagonismo das estratégias", ou seja, "usar as formas de resistência contra as diferentes formas de poder como um ponto de partida", utilizando as resistências como um catalisador para explicar "as relações de poder, localizar sua posição, descobrir seu ponto de aplicação e os métodos utilizados". Nesse sentido, todas as teses e dissertações analisadas exploram o conceito de modelo com o intuito de demarcar os limites entre o modelo tecnocrático e o modelo humanizado.

Davis-Floyd (2001), citada em muitas das teses e dissertações, descreve três paradigmas de assistência à saúde que coexistem nas nações industrializadas do Ocidente e que influenciam o parto e o nascimento contemporâneos: o modelo tecnocrático, o modelo humanizado e o modelo holístico. Neste texto, o enfoque é na comparação entre os dois primeiros modelos. O modelo tecnocrático de saúde, afirma Davis-Floyd, incorpora o sistema de valores da vida tecnocrática, cujos "sucessos são fundados na ciência, efetuada por tecnologia e realizada por meio de grandes instituições regidas por ideologias patriarcais em um contexto econômico com fins lucrativos". A obstetrícia, para a autora, como especialidade da medicina, repercute os valores culturais que colocam a tecnologia como prioridade. 
Nas teses e dissertações encontramos várias designações para nomear esse modelo de assistência obstétrica, dentre as quais destacamos as seguintes: "paradigma tecnocrático invasivo", "modelo hospitalar tecnocrático", "modelo médico de dominação do parto", "paradigma de atenção ao parto fundamentalmente intervencionista", "atual modelo de assistência ao parto, tecnológico e centrado no médico", "modelo médico, patriarcal e centralizador", "modelo tecnológico de nascimento", "modelo medicalizado de assistência", "modelo intervencionista no parto", "modelo médico de assistência", "paradigma corpomáquina de base científico-racionalista", "modelo médico de dominação do parto", "modelo masculino de cuidado", "modelo hegemônico", "modelo biomédico", "modelo técnico atual", "modelo do parto como evento de risco", "modelo de prevenção do parto", "modelo preventivo da distócia", "modelo dogmático de antecipação e prevenção do desastre", "modelo atual do risco sexual-reprodutivo no parto", "modelo da fisiologia patológica" ou "modelo tecnocrático".

As diversas denominações contêm alguns elementos em comum. A ideia de modelo, paradigma e racionalidade; a concepção científica mecanicista e o uso indiscriminado de tecnologia; a noção de gênero, com o uso dos adjetivos "patriarcal" e "masculino" para demarcar os processos de sujeição a que estão submetidas as mulheres nos serviços de saúde; um viés profissional, em que o saber/poder médico responde pela conformação do arcabouço discursivo que sustenta as concepções e práticas da obstetrícia moderna; a denúncia de que esse modelo exerce um tipo de autoridade porque tem caráter "centralizador", "hegemônico" de "dominação" em um local em que essa autoridade é inquestionável: o hospital, e denotando que as relações interpessoais que se constituem sob esse modelo são assimétricas; a acentuação da noção de "risco" e de "patologia" do ciclo reprodutivo feminino, cuja consequência imediata é a "medicalização" ou o excesso de intervenção na fisiologia do parto e nascimento. Nas dissertações e teses analisadas, o "modelo tecnocrático" vem associado à desumanização do parto e nascimento.

A assistência prestada à mulher durante o processo do nascimento sofreu modificações significativas através dos tempos, principalmente a partir do século $\mathrm{XX}$, com a institucionalização do parto e sua medicalização, com os avanços tecnológicos, e o desenvolvimento da medicina fetal. Criou-se um 'saber' médico na área de obstetrícia.

Observamos que, por um lado, o surgimento de novas técnicas e descobertas correspondeu à melhoria das condições de parto, mas por outro, configurou-se na desumanização do nascimento (Brüggemann, 1998, p.22).

Em seu conjunto, o uso desses adjetivos remete às 12 características do modelo tecnocrático destacadas por Davis-Floyd (2001, p.6-10): (1) a separação mente-corpo e (2) o corpo como máquina:

No hospital, o aparelho reprodutivo da mulher é tratado como uma máquina de nascimento, conduzida por habilidosos técnicos, dentro de parâmetros de tempo inflexíveis. A cérvix uterina é avaliada em intervalos regulares, pelo menos a cada duas horas, e algumas vezes, mais amiúde. Se a dilatação não progride em conformidade com determinados parâmetros de tempos, um soro com ocitocina é instalado porque a máquina está defeituosa. Em consonância com a metáfora do corpo humano como uma máquina, e as concepções tayloristas de organização do trabalho, os obstetras 
têm adotado um modelo de 'linha de montagem' no parto hospitalar (Osava, 1997, p.58; destaques no original).

Davis-Floyd (2001, p.6) afirma que o "princípio da separação" é o principal valor do modelo tecnocrático, que separa os sujeitos de seu contexto, a mente do corpo, o corpo em partes, o saber em especialidades, o sujeito do objeto, a mãe de seu bebê. A metáfora do corpo como máquina marca um princípio de diferenciação sexual, porque o corpo do homem é concebido como padrão e o corpo feminino é visto como um desvio, como defeituoso por natureza. Então, "o hospital tornou-se a fábrica, o corpo da mãe se tornou a máquina, e o bebê se tornou o produto de um processo de fabricação industrial" (Davis-Floyd, 2001, p.6). Como resultado dessa concepção, segundo a antropóloga, o parto e o nascimento são considerados mecanicamente imperfeitos, cabendo à obstetrícia moderna o desenvolvimento de instrumentos e de tecnologia para adequar o processo reprodutivo feminino ao "modelo de linha de montagem fabril".

O (3) paciente como objeto e (4) o distanciamento do paciente, como ilustra a citação a seguir:

Ainda hoje, ao ser admitida em trabalho de parto (TP) em um hospital público, de um modo geral, a mulher é afastada de seus familiares e submetida a uma série de procedimentos de indicação duvidosa. Como forma de adequar o TP ao funcionamento do hospital e aos horários dos profissionais sua fisiologia é modificada por intervenções que têm o objetivo de acelerá-lo, independente dos desejos da mulher ou de eventuais riscos para ela e para o bebê. Estas intervenções são geralmente executadas sem que a mulher seja informada sobre o que está sendo feito e é comum que permaneça abandonada no pré-parto sem nenhum tipo de suporte físico ou emocional. Com dor, em jejum, seminua, num ambiente estranho e com profissionais desconhecidos, a mulher não tem como vivenciar esta experiência senão como um sofrimento interminável. A ênfase dada apenas aos aspectos médicos, durante todo o acompanhamento do TP, parto e nos cuidados imediatos com o bebê é exagerada e ocorre em detrimento dos aspectos psicossociais da gravidez e do parto ... O atendimento compromete não apenas a mulher. Além de todas estas violências, após o nascimento, mãe e filho(a) são separados(as) para que sejam realizadas as rotinas de cuidados com o bebê, independente das necessidades fisiológicas e afetivas para que esse encontro se realize o mais depressa possível (Dias, 2006, p.50-51).

A mecanização do corpo e o princípio de separação da "tecnomedicina" acarretam a despersonalização dos sujeitos. Davis-Floyd (2001) aponta que, na formação em medicina, os estudantes são ensinados a não se envolver emocionalmente com seus "casos". A formação médica pressupõe ainda a separação e especificação do conhecimento sobre o sujeito, não permitindo a integralidade da assistência (Lampert, 2002). Essas características são tecnicamente aplicadas e disciplinarmente conduzidas no hospital (Foucault, 2000), o que evidencia outros aspectos do modelo tecnocrático apontados por Davis-Floyd (2001): (5) "diagnóstico e tratamento de fora para dentro" - primazia de recursos biomédicos, como fármacos e tecnologia, para atestar e resolver problemas de saúde; (6) "organização hierárquica" e "padronização do cuidado" - para o qual o saber e a autoridade médica são mais valorizados e reconhecidos que outros saberes e profissões, a hierarquização gera a padronização de procedimentos, mesmo que cada mulher seja um ser individual e singular, 
as rotinas impostas na dinâmica hospitalar acabam por causar a despersonalização do parto e do nascimento; (7) "autoridade e responsabilidade inerentes ao médico e não ao indivíduo que recebe o cuidado", o que acarreta a subordinação do indivíduo à autoridade médica e à instituição hospitalar. Esse modelo (8) supervaloriza a ciência e a tecnologia e concebe a assistência em saúde sob uma perspectiva intervencionista, que almeja (9) resultado em curto prazo.

No modelo tecnocrático (10), a morte é sinônimo de derrota, um sinal de que a natureza não foi completamente vencida e domada. Segundo Davis-Floyd (2001), quanto mais dominamos a natureza, mais temerários ficamos dos aspectos da natureza que não conseguimos controlar. E essa noção de que a morte é algo a ser vencido a todo custo reverbera, na assistência ao parto e nascimento, no discurso preponderante que justifica a utilização de tecnologias e práticas invasivas como forma de antecipação de riscos. A (11) hegemonia tecnomédica e (12) a intolerância com outras modalidades de assistência terminam por caracterizar o modelo tecnocrático.

Essa concepção de parto é diametralmente oposta à concepção da humanização do parto e nascimento, para a qual o padrão é o parto fisiológico, enquanto o parto cirúrgico é uma medida necessária em casos específicos - cerca de $15 \%$ do total dos partos de uma população. Nas teses e dissertações, o conjunto de propostas de mudança para a assistência obstétrica oriundas do discurso de humanização aparece sob a forma de modelo ou de paradigma com as seguintes designações: "paradigma mais voltado para o aperfeiçoamento da fisiologia do parto", "paradigma não intervencionista", "modelo fisiológico de acompanhamento no parto", "modelo contra-hegemônico", "paradigma emergente", "novo modelo que permita dar conta da saúde vista em sua positividade, complexidade e como um processo, como um fenômeno multidimensional que envolve e é determinado por aspectos físicos, biológicos, psicológicos, sociais, culturais e ambientais, todos estes interdependentes", "modelo de atenção à saúde com perspectiva humanista"; "modelo de saúde social, ético e equânime norteado pela inclusão e solidariedade", "novo modelo para o cuidado à saúde com vistas à integralidade e humanização das ações", "novo modelo de cuidar, humanístico e complexo", "modelo desmedicalizado", "modelo humanizado de atenção ao parto e nascimento", "modelo que permita à mulher maior autonomia e a exclusão de procedimentos desnecessários", "modelo centrado na mulher", "paradigma que olha o parto como uma prática assistencial", "modelo de humanização do parto e nascimento" - nomenclatura que adotaremos.

De acordo com Davis-Floyd (2001, p.10-15), esse modelo assistencial caracteriza-se pela (1) conexão entre mente e corpo e (2) a concepção do corpo como um organismo - os aspectos culturais, sociais e psicológicos da mulher impactam nos mecanismos de produção e inibição do trabalho de parto, por isso, o cuidado é voltado para atender a mulher em sua integralidade; (3) o paciente como um sujeito relacional - o contexto social e familiar da mulher é considerado na organização da assistência obstétrica, assim, estimula-se a presença do acompanhante de escolha da mulher durante e após o parto; (4) conexão e cuidado entre profissional e paciente - os profissionais devem inspirar segurança e respeito à mulher gestante e a sua família, mediante uma relação dialógica entre eles; (5) diagnóstico 
e tratamento de fora para dentro e de dentro para fora; (6) equilíbrio entre necessidades institucionais e individuais; (7) informação, tomada de decisão e responsabilidade compartilhada entre médico e paciente - a ideia de corresponsabilidade da assistência em saúde, ao profissional de saúde cabe prestar todas as informações necessárias e requisitadas pela mulher e por sua família, para que o processo de decisão seja compartilhado; (8) ciência e tecnologia contrabalançada com humanismo - a ciência e a tecnologia devem ser colocadas a serviço das necessidades humanas e utilizadas de forma criteriosa, avaliando-se a singularidade de cada indivíduo; (9) foco em ações preventivas - a abordagem preventiva procura diminuir os excessos de medicalização e de cirurgificação da vida, daí o incentivo à assistência pré-natal e à preparação da mulher/do casal para o parto e nascimento; (10) morte como um resultado aceitável; (11) cuidado orientado pela compaixão - Davis-Floyd utiliza o termo compassion para designar a capacidade de o profissional de saúde pôr-se no lugar daquele que é cuidado, no sentido de alteridade, empatia; (12) abertura para outras modalidades de assistência - o modelo humanístico amalgama tanto os avanços tecnológicos e científicos do modelo tecnocrático e as possibilidades terapêuticas do modelo holístico, como métodos não farmacológicos para o alívio da dor para a mulher em trabalho de parto (massagens, banhos etc.).

Nesse modelo, portanto, o parto deve ser respeitado em seu tempo, em um espaço em que a mulher se sinta segura e confortável (hospital, casa de parto, residência), com atendimento especializado e específico (singularizado, para ela), preferencialmente sem qualquer intervenção desnecessária (tricotomia, episiotomia, manobra de Kristeller etc.), com o emprego de tecnologias apropriadas (ambiente adequado e com instrumentos que potencializem mecanismos fisiológicos do parto), com a possibilidade de deambulação e de ingestão de líquidos e alimentos, permitindo e incentivando a presença de acompanhante da escolha da mulher, respeitando a liberdade da mulher para escolher a posição que desejar no período expulsivo, sem a indicação rotineira de cesariana (salvo se realmente necessário), estímulo ao contato pele a pele imediato entre mãe e bebê após o nascimento e clampeamento tardio do cordão umbilical, sem exames desnecessários no bebê logo ao nascer, com incentivo e apoio à mulher para o aleitamento materno, com respeito à privacidade e à intimidade da mulher e da família inerentes ao parto e nascimento, mediante o cuidado pela equipe de saúde de não expor a mãe a situações vexatórias e degradantes, e oportunidade para que a mãe e o acompanhante de sua escolha recebam o bebê em privacidade, prática de alojamento conjunto, acompanhamento na amamentação e encaminhamento para o atendimento pediátrico.

Diante do exposto, o modelo tecnocrático é caracterizado em oposição a um novo modelo de assistência obstétrica, que reformata a cena do parto, reposiciona os sujeitos, redefine atribuições e responsabilidades, propõe novas concepções de gestação, parto e nascimento. O novo modelo é considerado por suas defensoras e seus defensores uma superação, porque amalgama o sentido ritualístico do parto e do nascimento juntamente com o estatuto científico da medicina baseada em evidências e a perspectiva de direitos reprodutivos como direitos humanos. 


\section{Histórias e trajetórias do movimento de humanização do parto e nascimento no Brasil}

No contexto da década de 1990, no Rio de Janeiro, ocorreu a implantação da primeira maternidade "humanizada" do país, a Maternidade Leila Diniz, em 1994, considerada pioneira por suas concepções e práticas desmedicalizadas e com a inclusão de enfermeiras obstétricas na assistência ao parto. Uma situação peculiar no município do Rio de Janeiro, onde houve a articulação, a partir de 1992, entre a Secretaria Municipal de Saúde, as escolas que ministravam cursos de enfermagem obstétrica (em especial a Uerj) e o Instituto Municipal da Mulher Fernando Magalhães (IMMFM). A Secretaria Municipal de Saúde passou a ser gerenciada por um grupo de feministas (Dias, 26 set. 2013; Progianti, 27 set. 2013) que, entre outras pessoas, contava com a médica pediatra Katia Maria Ratto de Lima (que fez dissertação sobre o tema em 1997) e a enfermeira obstétrica, chefe do Serviço de Enfermagem do IMMFM e professora da Faculdade de Enfermagem da Uerj, Maysa Luduvice Gomes (com tese defendida em 2011 sobre humanização do parto). Em 1996, a Secretaria Municipal convida Marcos Augusto Bastos Dias (com tese sobre humanização da assistência defendida na Fiocruz em 2005) para assumir a direção da Maternidade Leila Diniz.

Essa vinculação de três autores selecionados para a nossa pesquisa é confirmada em entrevista por Jane Progianti. Principal orientadora na temática da humanização do parto, ${ }^{4}$ a professora da Uerj foi chefe do Serviço de Enfermagem do IMMFM de 1986 a 1992 (período que precede ao de Maysa Gomes na direção), oportunidade em que implanta o serviço de enfermagem na sala de parto, primeira experiência nesse sentido no Rio de Janeiro.

Por quatro anos eu fui chefe de serviço. E como chefe de serviço, eu tive condições, naquele contexto, de implementar a assistência de enfermagem na sala de parto de lá. Não tinha. Aqui no Rio de Janeiro, enfermeiras não trabalhavam na assistência ao parto e aí, eu, como chefe da Enfermagem, montei uma equipe, negociamos com os médicos e fomos trabalhar na sala de parto. No entanto, eu chamo esse momento de pré-humanização, porque ainda não se falava de humanização como se fala hoje (Progianti, 27 set. 2013).

É interessante apontar como a autora estabelece marcos para indicar quando se trata de "humanização" e quando ainda se está no processo de "pré-humanização". A humanização para ela começa a partir de 1992, quando ocorre a efetiva parceria entre a Secretaria Municipal de Saúde, o IMMFM e a Uerj, tendo como marco principal no país a criação da Rede pela Humanização do Parto e Nascimento, em 1993. "Mas foi possível se falar de humanização do parto e nascimento nessa época, de 1992 para cá, tanto que o movimento de humanização do parto e nascimento acontece e eu dou como marco a criação da Rehuna" (Progianti, 27 set. 2013). As feministas que integravam a secretaria municipal participavam da Rede pela Humanização do Parto e Nascimento (Rehuna), de acordo com entrevista de Leila Gomes Ferreira de Azevedo (com dissertação selecionada defendida em 2008) a Aline Bastos Porfírio (2011).

A dissertação de Porfírio (2011) oferece um quadro em detalhes do contexto carioca para o discurso de humanização. Dessa parceria entre serviço público, academia e poder público emerge um conjunto de ações e enunciados que visavam alterar as práticas e os discursos sobre assistência obstétrica. Katia Ratto de Lima e Maysa Luduvice Gomes participaram 
ativamente desse processo, tendo Marcos Augusto Bastos Dias se integrado a partir do momento em que assume a diretoria da Maternidade Leila Diniz, em 1996. O médico nomeou, em 1998, Leila Gomes Ferreira de Azevedo como chefe do Serviço de Enfermagem da maternidade. De acordo com Porfírio (2011, p.87-90), Azevedo participa também de um curso de capacitação nas casas de parto do Japão, promovido pela Japan International Cooperation Agency (Jica) em acordo com o Ministério da Saúde, e, ao retornar, assume a coordenação da Casa de Parto David Capistrano Filho, a primeira casa de parto pública da cidade do Rio de Janeiro, fundada em 2004. Já como coordenadora desse centro de parto normal, Leila Azevedo ingressa no curso de mestrado em Enfermagem na Uerj, onde estuda em sua dissertação o processo de implantação da referida Casa de Parto e as estratégias das enfermeiras obstetras para manutenção do modelo humanizado de assistência obstétrica e neonatal, sob orientação de Jane Márcia Progianti.

Tanto Leila Azevedo como Adriana Lenho de Figueiredo Pereira e Heloísa Ferreira Lessa (com teses selecionadas para a nossa análise) são enfermeiras obstétricas e têm suas trajetórias profissionais ligadas à Faculdade de Enfermagem da Uerj, onde se diplomaram especialistas. Os três trabalhos tratam do parto e nascimento fora do ambiente hospitalar. Pereira é professora adjunta da Faculdade de Enfermagem da Uerj desde 2003. Antes disso, trabalhou como enfermeira obstétrica no Hospital Universitário Pedro Ernesto da Uerj (1994-2005) e no Instituto Municipal da Mulher Fernando Magalhães (1989-1994) período que coincide com as chefias de Jane Progianti e Maysa Gomes. Em seu processo de doutoramento, estudou a luta das enfermeiras para implementação da Casa de Parto David Capistrano Filho no município do Rio de Janeiro (Pereira, 2007).

Heloisa Lessa (2012, p.19-22), por sua vez, tem inserção na assistência obstétrica domiciliar. Diferente dos sujeitos até aqui apresentados, cujas trajetórias profissionais desenvolvem-se nos serviços de saúde, Lessa tem atuado desde a sua graduação como profissional autônoma na preparação de gestantes para o parto, na assistência ao trabalho de parto e parto e na atenção ao puerpério. Sobre sua iniciação profissional na enfermagem obstétrica, a autora relata: "Já tínhamos como ideologia, na prática profissional, o respeito ao desejo da mulher, a mulher no comando e no centro do processo" (Lessa, 2012, p.20). Lessa afirma que após contato com o trabalho de Michel Odent passou a atender partos domiciliares em 1992. Em parceria com o obstetra francês, inclusive, ofereceu o curso de atualização "Ecologia do parto e nascimento" na cidade do Rio de Janeiro. Essa pesquisadora é uma das referências no Brasil na divulgação do parto domiciliar planejado, tendo participado junto com Odent, por exemplo, do filme $O$ renascimento do parto, lançado em 2013. Lessa integrou a diretoria da Rehuna no triênio 2012-2015, ocupando cargo no Conselho Diretor.

Notamos no relato acima e na trajetória dos demais sujeitos de pesquisa que a relevância da experiência profissional se tornou, para essas pessoas, um dispositivo que potencializou a procura pela formação acadêmica em nível de pós-graduação e motivou mudanças nas concepções e práticas assistenciais por elas desenvolvidas. Esses sujeitos também fazem referências ao movimento feminista de saúde e direitos reprodutivos. De modo geral, os trabalhos selecionados indicam que o enfoque em direitos reprodutivos, numa perspectiva feminista, tem pautado o debate em prol da assistência obstétrica humanizada. 
A dissertação e a tese de Carmen Simone Grilo Diniz (1997, 2001), ambas defendidas no programa de pós-graduação em Medicina Preventiva da USP, enfatizam a assistência obstétrica humanizada sob o ponto de vista dos direitos reprodutivos. A trajetória dessa pesquisadora, vinculada à Rede Feminista, também demonstra como o movimento feminista tem pautado as reivindicações da sociedade civil, incluída a academia, por qualidade na atenção à saúde da mulher.

Quando eu entrei na faculdade, eu tinha uma atração pela obstetrícia, fiz maternidade, fiz o curso de obstetrícia. Mas meu estágio foi muito traumático. Até descrevi isso na introdução da minha dissertação. Um dia, quando eu estava no sexto ano, saindo de um plantão, véspera de inscrição para residência, eu entro na biblioteca lá em Natal (eu estudava em Natal) [UFRN], dou de cara com o Boletim da Clap [Centro Latinoamericano de Perinatologia] chamado 'Las basis fisiológicas e psicológicas del manejo humanizado del parto natural', de Roberto Caldeyro-Barcia. É aquele negócio de o livro achar você, e não você achar o livro. Aí eu desbaratinei tudo o que estava fazendo para ler isso, e aí caíram todas as fichas ao mesmo tempo. Foi incrível! Eu desisti de fazer Ginecologia e Obstetrícia e fui fazer Saúde Coletiva. Você nunca sabe se foi a melhor escolha, mas foi a escolha daquela hora. Foi assim que eu entrei em contato. O fisiologista Roberto Caldeyro-Barcia foi o grande autor nisso e que dizia isso nessa versão de 1984 e que, na versão de 1979, já dizia tudo isso que dizemos agora. Muito bacana, muito radical, já usa o termo 'humanizado'. Foi assim que entrou. Naquela ocasião, também fazíamos parto em casa, havia muitos conhecidos com essa visão. Era uma coisa meio hippie na verdade. Então, foi assim que começou (Diniz, 30 out. 2013).

Com outra formação, mas também com doutorado na área de saúde pública, a enfermeira Ruth Hitomi Osava apresentou a tese mais antiga com a palavra "humanizado" no resumo. Com formação toda em São Paulo, Osava trabalhou durante 15 anos no Espírito Santo, onde desenvolveu alterações nos protocolos de atendimento de uma maternidade. Nos anos 1980, conheceu a parteira alemã Angela Gerhke, que trabalhava em uma comunidade da capital paulista na atenção a mulheres gestantes e parturientes. Também travou contato com a Jica, conforme entrevista concedida para a nossa dissertação. Em 1996, retornou a São Paulo, onde planejou, implantou e dirigiu a Casa de Parto de Sapopemba (1998-2003). Nesse mesmo período, coordenou o serviço de enfermaria do centro de parto normal da Maternidade Filantrópica Amparo Maternal, local em que treinou mais de 120 mil enfermeiras e demais profissionais de saúde de todo o país para assistência ao parto. Assim como as demais pesquisadoras, Osava (1 nov. 2013) destaca em entrevista o mal-estar que sentia ao assistir partos no modelo tecnocrático e a necessidade de buscar e pesquisar referenciais que respondessem a sua angústia.

Não sei se estão nessa sequência, mas são coisas que se encadearam em algum momento. 1980... No período da minha dissertação, eu observava o seguinte, eu fazia a pergunta: por que esse parto que eu assisto no hospital me incomoda? Por que eu não gostaria de ter um parto assim? E aí eu fiz esta mesma pergunta na minha dissertação para as minhas colegas, para enfermeiras obstetras que trabalhavam em maternidade privada e em maternidade pública ... Aí eu fui perguntar para elas o que elas achavam do parto normal e se elas pudessem ter algum tipo de parto, qual elas prefeririam, por quê? Elas falavam quase uníssonas que todas queriam parto normal, porque era 
mais natural. Todas em relação ao paciente. 'Eu sempre recomendo o parto normal, é melhor para a paciente'. 'E se fosse para você?' Elas agiam diferente: 'Eu não queria o parto normal'. Eram exceções as meninas que queriam parto normal. 'Por que você não queria o parto normal para você?'. 'Ah, porque a gente vê que pode não dar certo. A gente vê alguns partos com toda aquela dor e no final que virou cesariana. Eu acho que é mais prático, já que pode virar cesariana, que venha cesariana logo'. Elas não levavam muito em conta a qualidade da experiência. Outra coisa que elas falavam é que elas não queriam a violência do parto. Todo mundo sabia que tinha violência. Só que a gente achava que era no outro, que a violência era no outro. E de alguma maneira a gente achava que era assim mesmo, que era parte do atendimento aquilo que a gente não dava o nome de violência. Tinha até um nome de ajudar a mulher, de protegê-la, quando a mulher estava meio enlouquecida a gente tinha que trazer para a normalidade, para a razão, como se ela fosse uma paciente psiquiátrica. E que toda aquela loucura, aquele absurdo de amarrar, prender, empurrar a barriga fazia parte de alguém que estava lidando com bicho. Uma mulher enlouquecida pela dor, porque estava sozinha, sem acompanhante... A gente não tinha nome para as coisas, como hoje você tem categorias e conceitos tão claros. Naquele tempo era muito confuso. Era assim: um sentimento. Eu falo do meio da década de 1980. Um sentimento que me incomoda. E o que me incomoda... Não sei se é o Érico Veríssimo que diz assim: 'você se define por aquilo que não te causa estranhamento'. Então, aquilo me incomodava e eu comecei a procurar e a pesquisar.

Por sua vez, o contexto das pesquisadoras de Florianópolis guarda direta relação com a implantação da Maternidade do Hospital Universitário da UFSC, inaugurada em 24 de outubro de 1995. Essa maternidade, segundo Tornquist (2004, p.169-170), seguiu o exemplo da Maternidade Leila Diniz, fundada em 1994 na cidade do Rio de Janeiro, ao garantir para a gestante o direito de escolher o acompanhante para o seu processo de parto:

A experiência dessa Maternidade [Leila Diniz] na adoção de uma perspectiva humanizadora foi muito bem sucedida e serviu de exemplo para a Maternidade do Hospital Universitário de Florianópolis. A partir de contatos que, já à época, transitavam pela Rehuna, foram trazidos profissionais da Leila Diniz para assessorias e conferências com a equipe de saúde do HU, dentro da estratégia de convencimento dos profissionais mais arredios às inovações propostas pelo Grupo Interdisciplinar de Florianópolis, particularmente o parto de cócoras e a figura do acompanhante no parto.

A dissertação de Odaléa Brüggemann informa que o tema do acompanhante de escolha da gestante foi um ponto polêmico no processo de implantação da maternidade do Hospital Universitário da UFSC. Motivo pelo qual os médicos Jean Ruffie, da Maternidade Leila Diniz, e Hugo Sabatino, da Universidade Estadual de Campinas (Unicamp), foram chamados "na tentativa de sensibilizar os obstetras e desmistificar o receio sobre o acompanhante" (Brüggemann, 1998, p.17). Essa citação foi retirada do item de abertura da dissertação de Brüggemann, no qual a pesquisadora destaca sua trajetória, relatando algo comum nos trabalhos analisados: o incômodo com o modo de atenção às gestantes e parturientes em uma dada fase da experiência profissional e sua transformação mediante o contato com a "humanização" da assistência obstétrica e da inserção na pesquisa acadêmica. 
Em 1985, surgiu a oportunidade de trabalhar na Maternidade Carmela Dutra (MCD) em Florianópolis ... Foi quando iniciei minhas atividades assistenciais em obstetrícia, cuidando de mulheres gestantes/parturientes e famílias, e também assumindo a chefia do setor do Centro Obstétrico ... sentia-me muito angustiada com as manifestações de medo, sofrimento, angústia e ansiedade que as mulheres demonstravam durante a evolução do trabalho de parto e do parto propriamente dito. Comecei a perceber que a minha ansiedade não era gerada apenas pela sensação de 'impotência' diante de algumas situações que eram e são consideradas 'fisiológicas', numa visão biologicista, mas também pela falta de conhecimento e habilidade técnica para acompanhar os períodos clínicos do parto ... Cabe ressaltar que, quando iniciei minhas atividades na MCD, não havia enfermeira obstétrica no serviço, sendo a assistência, durante o processo do nascimento, desenvolvida por médicos obstetras e neonatalogistas, parteiras e demais membros da equipe de enfermagem, enfermeiras generalistas e acadêmicos de medicina e de enfermagem ... Em 1993, fui admitida como professora auxiliar na Universidade Federal de Santa Catarina, através de concurso público para a área de enfermagem obstétrica ... Em março de 1994 iniciei minhas atividades no HU da UFSC, como representante do Departamento de Enfermagem na Comissão Multiprofissional de Assessoria para a Implantação da Maternidade ... tendo como parceiras a prof. Maria de Fátima Mota Zampieri e a prof. Maria Emília de Oliveira ... Buscando conhecer outras experiências e propostas de atendimento à mulher, que pudessem ser adaptadas na maternidade, visitei a maternidade do Hospital das Clínicas de Porto Alegre, a maternidade Leila Diniz no Rio de Janeiro, e a Casa de Partos Nove Luas, Lua Nova em Niterói. Ainda participei de eventos, entre eles, o II Encontro de Parto Humanizado em Campinas - São Paulo, pois cada vez mais me interessava por experiências e estudos relacionados com a humanização da assistência obstétrica. Neste período, também participava, de forma esporádica, das reuniões da Rede de Humanização do Parto e Nascimento (Rehuna) ... O trabalho e a dedicação de todos os profissionais integrantes da comissão possibilitaram, em 24 de outubro de 1995, a abertura da Maternidade do HU ... Desde então, desenvolvo minhas atividades de Ensino, Pesquisa e Extensão nessa unidade. A maternidade procura atender o binômio mãe-filho dentro da filosofia preconizada, tornando-se uma geradora de mudanças na assistência e no ensino de obstetrícia, nas diversas áreas profissionais, possuindo como princípios norteadores da sua filosofia a Humanização e Interdisciplinaridade (Brüggemann, 1998, p.14-18).

A enfermeira e docente Maria de Fátima Mota Zampieri, mencionada anteriormente, defendeu sua tese em 2006, tendo como tema a assistência humanizada no pré-natal. A pesquisadora é professora do Departamento de Enfermagem da UFSC desde 1994, onde também cursou o mestrado e o doutorado. Antes de ingressar na carreira docente, atuou como enfermeira no Hospital Colônia Santana, quando passou a defender a reforma psiquiátrica e a humanização da assistência psiquiátrica. Também trabalhou como enfermeira obstétrica na Maternidade Darcy Vargas exercendo o cargo de supervisora e chefe de Seção de Enfermagem, ocasião em que cursou a Especialização em Enfermagem Obstétrica, Perinatal e Obstetrícia Social na Universidade do Vale do Itajaí (Univali). Participou do "comitê estadual de mortalidade materna, da comissão municipal de atenção à saúde da mulher para implantação de protocolos nesta área, da capacitação de funcionários da rede hospitalar e da atenção básica, articulando o ensino, a extensão e a pesquisa" (Zampieri, 2006, p.3). Posteriormente, já como docente da UFSC, publicou em 
2001 o livro A melodia da humanização: reflexões sobre o cuidado no processo de nascimento em coautoria com as professoras da UFSC Odaléa Brüggemann e Maria Emília de Oliveira.

Toda esta bagagem pessoal e profissional direcionou meus estudos para a humanização e para a atenção à saúde da mulher, sobretudo no pré-natal, dois temas apaixonantes que transito com muita dedicação, procurando desvelá-los.

A constatação durante essas vivências da existência de um movimento no âmbito da saúde que valorizava as relações interpessoais e os seres humanos e contrapunha-se à massificação e homogeinização das pessoas, à compartimentalização dos saberes, à violência social e pessoal e à marginalização também contribuiu para que meus conhecimentos sobre este tema fossem aprofundados (Zampieri, 2006, p.3).

Esses trabalhos, principalmente os pioneiros, estabelecem um corte epistemológico pelo novo paradigma de atendimento ao parto e nascimento. Os sujeitos relatam momentos de transição acadêmica e profissional, da formação em nível de graduação em um "modelo tradicional" de assistência obstétrica à necessidade de incorporação de outro modelo, que "resgate" as relações intersubjetivas entre profissionais de saúde e a mãe gestante/ parturiente. Essas trajetórias também convergem para a constituição de referenciais críticos ao "modelo tradicional" por meio de pesquisas sobre humanização da assistência obstétrica e neonatal. Palavras como "mudança", "resgate", "transição", "inovações" permeiam os textos analisados. Essa divisão, que estabelece marcos de quais posições discursivas os sujeitos ocupavam antes de travar contato com a humanização (ou práticas humanizadas) e depois da humanização, reflete-se na alteração de concepção de um conjunto de práticas obstétricas, criando por isso enclaves de determinação de um objeto de discurso e, ainda, forjando uma "vontade de saber" que serve para a constituição de conceitos abstratos e operativos. Essa transição está presente também na caracterização paradigmática que esses sujeitos visam constituir, o que, por conseguinte, lança conceitos, objetos e trajetórias dentro da reconfiguração de um novo lugar de fala que se materializa entre outros lugares nas disputas acadêmicas e profissionais sobre que "modelo" é mais adequado para o parto e nascimento e qual profissional pode realizar o melhor acompanhamento à mulher, ao bebê e à família.

\section{Considerações finais}

De modo geral, os sujeitos, em suas teses ou dissertações, procuram justificar a escolha pelo objeto de pesquisa por meio de suas trajetórias. No texto de abertura dos trabalhos, há relatos de experiências profissionais, acadêmicas e políticas que indicam lugares institucionais ocupados. Portanto, ao enunciar as posições que ocuparam, as pesquisadoras querem também evidenciá-las; num duplo sentido de quem justifica o trabalho e pretende autorização para o que fala. Ainda, cada trabalho traz testemunhos de histórias de vida que se concatenam no desenvolvimento do campo de pesquisas sobre humanização do parto e nascimento no Brasil, bem como na implementação de políticas de saúde em suas respectivas regiões. Nos textos analisados aparece a preocupação em justificar a necessidade de estudar e investigar a assistência ao parto e nascimento, tomando por base dilemas que enfrentaram em suas práticas profissionais. Elas relatam 
sentimentos de "angústia" ao assistirem partos de acordo com o "modelo tradicional", dentro do qual foram formadas.

Os 11 trabalhos selecionados para descrição qualitativa têm em comum o fato de testemunharem momentos de transição na vida das pesquisadoras, em que o projeto de construção de outro modelo de cuidado obstétrico tornou-as referência, portanto, reconhecidas publicamente em suas áreas de atuação. A própria posição que essas pesquisadoras ocupam no discurso de humanização da assistência obstétrica e neonatal orientou nosso recorte de teses e dissertações. Pois, como nossa intenção foi descrever, caracterizar, delimitar quais enunciados estão subjacentes ao arcabouço denominado discurso de humanização do parto e nascimento, priorizamos aquelas pessoas que têm uma trajetória pública reconhecida vinculada ao movimento que discute mudanças na assistência ao parto e nascimento no Brasil.

Grande parte das pesquisadoras selecionadas tem em comum a graduação no final dos anos 1970 e início dos anos 1980, uma primeira experiência no serviço público tradicional e, depois, uma transformação de suas posições a partir de inquietações que emergem de suas práticas. É assim que elas costumam relacionar suas pesquisas na academia, a busca por respostas aos questionamentos da prática cotidiana na assistência obstétrica e referências para pensar novas práticas. Cada pesquisadora relaciona sua trajetória ao processo de implantação e desenvolvimento das políticas e movimentos sociais de humanização nas cidades em que atuam (Rio de Janeiro, São Paulo e Florianópolis), o que entremeia biografia e história do desenvolvimento desse modelo de assistência.

Por fim, salientamos que este estudo enfatiza os centros de pesquisa e as áreas de conhecimento com maior produção quantitativa de teses e dissertações no Brasil. Essa demarcação dos centros e da área (ciências da saúde) que mais produz sobre a temática de humanização do parto e nascimento é um dos resultados do presente artigo, ainda que, por outro lado, ofereça limites quanto a não integrar contribuições importantes e originais de pesquisadoras que não estão nos centros de referência e em áreas que não a de saúde. Sob esse aspecto, instigamos outros estudos sobre as trajetórias de pesquisadoras não contempladas devido aos métodos de seleção aqui aplicados.

\section{AGRADECIMENTO}

O presente trabalho foi realizado com apoio da Coordenação de Aperfeiçoamento de Pessoal de Nível Superior - Brasil (Capes); código de financiamento 001.

\section{NOTAS}

${ }^{1}$ Conforme dados do Geocapes, em 2012 as ciências da saúde possuíam maior número de programas de pós-graduação no país. Além desse fator, a concentração de trabalhos sobre humanização do parto e nascimento nas ciências da saúde (79\%) também se relaciona com a formação e a prática de profissionais da saúde, especialmente da enfermagem. O número elevado de trabalhos nessa área enfatiza o projeto político profissional da enfermagem em fortalecer a atuação da enfermeira obstétrica na assistência ao parto e nascimento de baixo risco e se coaduna a ações do governo federal desde o final da década de 1990 em ampliar a formação de enfermeiros, especialmente em enfermagem obstétrica (Brasil, 2012).

${ }^{2}$ Os 13 trabalhos apresentados entre 1996 e 1999 representam 4\% do total de teses e dissertações sobre o tema no período de 1987 a 2012. A produção se consolida a partir de 2000, em convergência com a instituição de programas de humanização do governo federal, tais como: Programa de Humanização do Pré-natal 
e Nascimento (2000), Parto, Aborto e Puerpério, Assistência Humanizada à Mulher e ao Recém-nascido (2001), Programa de Humanização da Assistência Hospitalar (2001), Política Nacional de Humanização (2003) (Bourguignon, Grisotti, 2016).

${ }^{3}$ Para uma leitura sobre o contexto nacional de emergência do movimento pela humanização do parto e nascimento no Brasil, ver Bourguignon e Grisotti (2016); e sobre as concepções de humanização do parto e nascimento nas teses e dissertações brasileiras, ver Bourguignon e Grisotti (2018).

${ }^{4}$ Progianti orientou dez dissertações no período estudado.

\section{REFERÊNCIAS}

AYRES, José Ricardo de C.M.

Organização das Ações de Atenção à Saúde: modelos e práticas. Saúde e Sociedade, v.18, supl.2, p.11-23. Disponível em: <http://www. scielo.br/scielo.php?script=sci_arttext\&pid =S0104-12902009000600003\&lng=en\&nrm=i so>. Acesso em: 10 out. 2014. 2009.

AZEVEDO, Leila Gomes Ferreira de. Estratégias de luta das enfermeiras obstétricas para manter o modelo desmedicalizado na Casa de Parto David Capistrano Filho. Dissertação (Mestrado em Enfermagem) - Universidade do Estado do Rio de Janeiro, Rio de Janeiro. 2008.

BOURGUIGNON, Ana Maria.

Humanização do parto e nascimento: os discursos construídos nas teses e dissertações brasileiras. Dissertação (Mestrado em Sociologia Política) - Universidade Federal de Santa Catarina, Florianópolis. 2014.

BOURGUIGNON, Ana Maria; GRISOTTI, Marcia.

Concepções sobre humanização do parto e nascimento nas teses e dissertações brasileiras. Saúde e Sociedade, v.27, n.4, p.1230-1245. Disponível em: <http://www.scielo.br/ scielo.php?script $=$ sci_arttext $\&$ pid $=$ S010412902018000401230\&lng $=$ pt\&nrm $=$ iso $>$. Acesso em: 21 jan. 2019. 2018.

\section{BOURGUIGNON, Ana Maria; GRISOTTI,} Marcia.

A emergência do discurso de humanização do parto e nascimento nas teses e dissertações brasileiras (1987-2012). Publicatio UEPG:

Ciências Sociais Aplicadas, v.24, n.3, p.345-356. Disponível em: <http://www.revistas2.uepg. br/index.php/sociais/article/view/8951/5552>. Acesso em: 2 ago. 2018. 2016.

BRASIL.

Ministério da Educação. Coordenação de Aperfeiçoamento de Pessoal de Ensino Superior. Geocapes: Sistema de Informações Georreferenciadas. Brasília: Ministério da Educação. Disponível em: <https://geocapes. capes.gov.br/geocapes/>. Acesso em: 8 ago. 2018. 2012.
BRÜGGEMANN, Odaléa Maria. A enfermagem como diálogo vivo: uma proposta humanística no cuidado à mulher durante o processo do nascimento. Dissertação (Mestrado em Enfermagem) - Universidade Federal de Santa Catarina, Florianópolis. 1998.

DAVIS-FLOYD, Robbie.

The technocratic, humanistic and holistic paradigms of childbirth. International Journal of Gynecology and Obstetrics, v.71, supl.1, p.S5-S23. Disponível em: <http://www.davis-floyd.com/ wp-content/uploads/2017/02/Davis-Floyd-2001The-Technocratic-Humanistic-and-HolisticModels-of-Birth.pdf>. Acesso em: 8 ago. 2018. 2001.

DIAS, Marcos Augusto Bastos.

[Depoimento]. Entrevistadora: Ana Maria Bourguignon. Rio de Janeiro, IFF/Fiocruz. 1 arquivo em mp3 (62 min). Depoimento concedido para a dissertação Humanização do parto e nascimento: os discursos construídos nas teses e dissertações brasileiras. 26 set. 2013.

DIAS, Marcos Augusto Bastos.

Humanização da assistência ao parto: conceitos, lógicas e práticas no cotidiano de uma maternidade pública. Tese (Doutorado em Saúde Coletiva) - Fundação Oswaldo Cruz, Rio de Janeiro. 2006.

DINIZ, Carmen Simone Grilo.

[Depoimento]. Entrevistadora: Ana Maria Bourguignon. Florianópolis, UFSC. 1 arquivo em mp3 (69 min). Depoimento concedido para a dissertação Humanização do parto e nascimento: os discursos construídos nas teses e dissertações brasileiras. 30 out. 2013.

DINIZ, Carmen Simone Grilo.

Humanização da assistência ao parto no Brasil: os muitos sentidos de um movimento. Ciência e Saúde Coletiva, v.10, n.3, p.627637. Disponível em: <http://www.scielo.br/ scielo.php?script=sci_arttext\&pid $=$ S1413$81232005000300019 \& \operatorname{lng}=$ en $\& \mathrm{nrm}=\mathrm{iso}>$. Acesso em: 1 ago. 2018. 2005. 
DINIZ, Carmen Simone Grilo.

Entre a técnica e os direitos humanos: possibilidades e limites da humanização da assistência ao parto. Tese (Doutorado em Medicina Preventiva) - Universidade de São Paulo, São Paulo. 2001.

DINIZ, Carmen Simone Grilo.

Assistência ao parto e relações de gênero: elementos para uma releitura médico-social. Dissertação (Mestrado em Medicina Preventiva) Universidade de São Paulo, São Paulo. 1997.

FOUCAULT, Michel.

A ordem do discurso. São Paulo: Loyola. 2011.

FOUCAULT, Michel.

A arqueologia do saber. Rio de Janeiro: Forense Universitária. 2005.

FOUCAULT, Michel.

A microfísica do poder. Rio de Janeiro: Graal. 2000.

FOUCAULT, Michel.

O sujeito e o poder. In: Dreyfus, Hubert L.; Rabinow, Paul. Michel Foucault, uma trajetória filosófica: para além do estruturalismo e da hermenêutica. Rio de Janeiro: Forense Universitária. p.231-249. 1995.

GOMES, Maysa Luduvice.

A prática obstétrica da enfermeira no parto institucionalizado: uma possibilidade de conhecimento emancipatório. Tese (Doutorado em Enfermagem) - Universidade Federal do Rio de Janeiro, Rio de Janeiro. 2011.

LAMPERT, Jadete B.

Tendências de mudanças na formação médica no Brasil. São Paulo: Hucitec. 2002.

LESSA, Heloisa.

A saúde da mulher e a opção pelo parto domiciliar planejado. Tese (Doutorado em Enfermagem) Universidade Federal do Rio de Janeiro, Rio de Janeiro. 2012.

LIMA, Katia M. Ratto de

Maternidade Leila Diniz 1994 a 1996: nascimento de um novo profissional de saúde? Dissertação (Mestrado em Saúde Coletiva) - Fundação Oswaldo Cruz, Rio de Janeiro, 1997.

OSAVA, Ruth Hitomi.

[Depoimento]. Entrevistadora: Ana Maria Bourguignon. Florianópolis, UFSC. 1 arquivo em mp3 (59 min). Depoimento concedido para a dissertação Humanização do parto e nascimento: os discursos construídos nas teses e dissertações brasileiras. 1 nov. 2013.

OSAVA, Ruth Hitomi.

Assistência ao parto no Brasil: o lugar do não médico. Dissertação (Mestrado em Saúde Pública) - Universidade de São Paulo, São Paulo. 1997.

PAIM, Jairnilson S.

Modelos assistenciais: reformulando o pensamento e incorporando a proteção e a promoção da saúde. In: Seminários Temáticos Permanentes, 2001, Brasília. Anais... Brasília: Anvisa; Instituto de Saúde Coletiva/UFBA. p.116. Disponível em: <https://repositorio.ufba. br/ri/bitstream/ri/6168/1/Paim\%20JS.\%20 Texto\%20Modelos\%20Assistenciais.pdf $>$. Acesso em: 8 ago. 2018. 2001.

PEREIRA, Adriana Lenho de Figueiredo. Processo de implantação da casa de parto no contexto do Sistema Único de Saúde: uma perspectiva do referencial teórico de Gramsci. Tese (Doutorado em Enfermagem) Universidade Federal do Rio de Janeiro, Rio de Janeiro. 2007.

PORFÍRIO, Aline Bastos.

A atualização do habitus da enfermeira obstétrica no processo de implantação do modelo humanizado na maternidade Alexander Fleming (1998-2004).

Dissertação (Mestrado em Enfermagem) Universidade do Estado do Rio de Janeiro, Rio de Janeiro. 2011.

PROGIANTI, Jane M.

[Depoimento]. Entrevistadora: Ana Maria Bourguignon. Rio de Janeiro, Uerj. 1 arquivo em mp3 (101 min). Depoimento concedido para a dissertação Humanização do parto e nascimento: os discursos construídos nas teses e dissertações brasileiras. 27 set. 2013.

TORNQUIST, Carmen S.

Parto e poder: o movimento pela humanização do parto no Brasil. Tese (Doutorado em Antropologia Social) - Universidade Federal de Santa Catarina, Florianópolis. 2004.

ZAMPIERI, Maria de Fátima Motta. Cuidado humanizado no pré-natal: um olhar para além das divergências e convergências. Tese (Doutorado em Enfermagem) - Universidade Federal de Santa Catarina, Florianópolis. 2006.

\section{$\rightarrow \rightarrow \rightarrow<<<$}

